\title{
Irisin may have a role in pubertal development and regulation of reproductive function in rats
}

\author{
Nazife Ulker ${ }^{1}$, Ahmet Yardimci ${ }^{1}$, Nalan Kaya Tektemur², Ozgur Bulmus ${ }^{1}$, Seyma Ozer Kaya ${ }^{3}$, \\ Funda Gulcu Bulmus ${ }^{4}$, Gaffari Turk ${ }^{3}$, Mete Ozcan ${ }^{5}$ and Sinan Canpolat ${ }^{1}$ \\ ${ }^{1}$ Department of Physiology, Faculty of Medicine, Firat University, Elazig, Turkey, ${ }^{2}$ Department of Histology and \\ Embryology, Faculty of Medicine, Firat University, Elazig, Turkey, ${ }^{3}$ Department of Reproduction and Artificial \\ Insemination, Faculty of Veterinary Medicine, Firat University, Elazig, Turkey, ${ }^{4}$ Vocational School of Health Services, \\ Firat University, Elazig, Turkey and ${ }^{5}$ Department of Biophysics, Faculty of Medicine, Firat University, Elazig, Turkey \\ Correspondence should be addressed to S Canpolat; Email: sinancanpolat@firat.edu.tr
}

\begin{abstract}
Physical exercise and body muscle/fat mass are known to affect the endocrine system, puberty onset and reproductive health. However, the potential effects of irisin, an adipo-myokine and exercise-induced hormone, have not yet been fully elucidated on reproductive maturation. Therefore, the present study aimed to determine the effects of irisin administration on pubertal maturation and reproductive system in female and male rats. Daily i.p. injection of irisin (100 ng/kg; from postnatal day 21 for about 10 weeks) delayed the ages at the vaginal opening (as an external index of puberty onset) and first estrus. Furthermore, continuous administration of irisin to female rats caused a significant decrease in serum follicle-stimulating hormone levels and an increase in serum luteinizing hormone and $17 \beta$-estradiol levels, as well as causing histopathological changes in the ovarian tissue. On the contrary, irisin administration to male rats did not modify the timing of puberty, as estimated by age at preputial separation. However, chronic exposure to irisin produced significant increases in serum luteinizing hormone and testosterone levels and also sperm concentration and seminiferous tubule diameter in male rats. In conclusion, irisin exposure has different effects on both pubertal maturation and reproductive system in female and male rats. The present findings reveal that chronic irisin exposure may lead to disorders in the female reproductive system and may have androgenic potential on the hypothalamic-pituitary-gonadal axis in males. Reproduction (2020) $\mathbf{1 6 0} 281-292$
\end{abstract}

\section{Introduction}

The individual's sexual maturity is completed physiologically and the ability to reproduce is acquired with the transition to puberty (Patton \& Viner 2007). Metabolic status, body energy reserves, body fat/muscle mass and exercise play important roles in the transition to puberty and fertility. Especially states of negative balance (e.g. malnutrition) and/or very excessive physical activity cause delays in pubertal development (Roa \& TenaSempere 2014, Georgopoulos \& Roupas 2016, Witkoś \& Wróbel 2019). The effects of various metabolic signals that are associated with body weight and metabolic status (like leptin, ghrelin and insulin) were determined on the onset of puberty, whose mechanism is still unclear. These metabolic signals regulate the onset of puberty by affecting the hypothalamus-pituitary-gonadal (HPG) axis when the body fat and muscle mass exceed a critical limit in children (Wahab et al. 2016).

Irisin was discovered by Boström et al. (2012) and is a polypeptide hormone with 112 amino acids (Boström et al. 2012). Irisin is an adipo-myokine that is shown as a possible link between physical exercise and energy homeostasis and is the proteolytic product of fibronectin type III domain containing 5 (FNDC5). Exercise or cold exposure increases the irisin concentration in the circulation by inducing the FNDC5 gene expression in the skeletal muscle. Irisin increases thermogenesis and energy consumption by stimulating the conversion of white fat to brown fat (which is known as 'browning') (Boström et al. 2012, Lee et al. 2014, Ferrante et al. 2016). In addition to skeletal muscle and adipose tissue, irisin is also expressed in tissues like ovaries, testicle, epididymis and Leydig cells. Irisin levels may vary in children and adults according to body weight, BMI, fat mass, gender and exercise (Anastasilakis et al. 2014, Aydin et al. 2014).

Physical exercise may affect the endocrine system in both men and women (Enea et al. 2011). It is known that long-term and high-intensity physical exercise or excessive energy consumption cause delays in the onset of puberty and amenorrhea in women (Enea et al. 2011). In males, on the other hand, the data on the effects of physical activity on pubertal maturation are limited and 
there are few studies reporting that the transition to puberty is delayed or not affected depending on the type or intensity of the physical activity (Gurd \& Klentrou 2003, Georgopoulos \& Roupas 2016). In preclinical studies, however, it was reported that exercises at various severity reduced or increased the testosterone (TS) and luteinizing hormone (LH) levels and that cold exposure delayed reproductive development (Manna et al. 2004, Allouh 2015, Zhang et al. 2015). For this reason, we assume that the irisin hormone that is activated depending on exercise or cold exposure may play a role in the onset of puberty and on the reproductive function, especially when it is considered that this hormone is released from the muscle and fat tissue and increases energy consumption.

There are limited number of studies that investigate the effects of irisin hormone on reproductive functions. It is stated in various studies that irisin may be stimulating on ovaries, but may also reduce the reproductive hormones and sperm concentration in males (Poretsky et al. 2017, Tekin et al. 2019).

Taking the previously mentioned information into consideration, further studies using additional animal models are needed to evaluate the potential role of the irisin hormone on the transition to puberty and on the reproductive system. In the present study, the purpose was to comprehensively investigate the effects of irisin on the transition to puberty and on the reproductive system in animal models. It was aimed to determine the effects of chronic irisin administration on the pubertal development, sexual maturation, sperm parameters, reproductive hormones, ovarian and testicular tissues and reproductive organ weights in male and female rats.

\section{Materials and methods}

\section{Animals}

Prepubertal Sprague-Dawley female and male rats, aged 21 days and weighing $35 \pm 2 \mathrm{~g}$, were purchased from the University of Firat Experimental Research Unit (Elazig, Turkey). The animals were weaned at postnatal day (PND) 21 and housed by sex in standard polycarbonate cages (three rats/cage). During the study, the animals were kept under controlled environment at room temperature $\left(21 \pm 1^{\circ} \mathrm{C}\right)$ with $55 \pm 5 \%$ humidity and an automatically controlled $12 \mathrm{~h}$ light: $12 \mathrm{~h}$ darkness cycle (lights from $0700 \mathrm{~h}$ to $1900 \mathrm{~h}$ ). Pelleted food and tap water were provided ad libitum. All experiments were carried out with the approval of Firat University Ethical Committee (31.01.2018, number 19), and the rats were treated in accordance with the national and international laws and policies on the care and use of laboratory animals.

\section{Irisin injections}

Female and male rats were distributed into either the irisin group or the control group, with 12 animals in each group. Rats were given i.p. injections with $100 \mathrm{ng} / \mathrm{kg}$ irisin (SRP8039,
Sigma-Aldrich) (in deionized water; $1 \mathrm{~mL} / \mathrm{kg}$ ) or vehicle (saline) daily at 1300-1500 h from PND 21 for about 10 weeks. The dose of the irisin $(100 \mathrm{ng} / \mathrm{kg})$ was adjusted according to the dose used in the other study (Liu et al. 2017). The flow diagram of the experimental works is shown in Fig. 1.

\section{Assessment of onset of puberty and estrous cycle}

Starting at PND 30, changes in genital morphology were monitored for determining the puberty onset in all prepubertal female and male rats. Therefore, vaginal opening (complete canalization of the vagina) and preputial separation (separation of the prepuce from the glans penis), used as external indexes of puberty onset, were inspected daily in female and male rats, respectively (Korenbrot et al. 1977, Ojeda \& Urbanski 1994). The ages and body weights at which vaginal opening and preputial separation occurred in all rats were recorded. Thereafter, to examine the possible effects of irisin on first estrus and estrous cyclicity, vaginal lavages from female rats were obtained and viewed under a microscope daily (1000-1200 h) for 15 days starting on the day of vaginal opening. Therefore, the onset of cyclicity in all female rats began once the vaginal opening had occurred (PND 46-56). The characterization of each phase of estrous cycle (metestrus/diestrus, proestrus or estrus) is based on the proportion among three types of cells observed in a vaginal smear: leukocytes, nucleated epithelial cells and cornified cells (Marcondes et al. 2002).

\section{Determining the displaying time of first sexual behavior and formation time of first sperm in male rats via sexual behavior test}

After determining the pubertal timing, sexual behavior tests were carried out daily for $30 \mathrm{~min}$ to determine displaying time of first sexual behavior and formation time of first sperm in all male rats. All sexual behavior tests were performed individually between 1500 and $1700 \mathrm{~h}$ in the home cage of male with a sexually receptive female rat. Stimulus ovariectomized females were made sexually receptive by s.c. injections of 10 $\mu \mathrm{g}$ estradiol benzoate and $500 \mu \mathrm{g}$ progesterone $(48 \mathrm{~h}$ and $4 \mathrm{~h}$ before sexual behavior tests, respectively dissolved in $0.1 \mathrm{~mL}$ sesame oil), prior to the start of each sexual behavior test (Jones et al. 2013). These receptive females were used to serve only as sexual partners during sexual behavior tests of male rats. Determining the displaying time of first sexual behavior was based on showing intromission (vaginal penetration). When mating occurred (displaying of ejaculation), vaginal smear of each ovariectomized female was examined for the presence of sperm. The day when sperm were found in the vaginal smear was considered as formation time of first sperm of the mating animal.

\section{Blood sampling and reproductive organ collection}

All the rats were killed by decapitation at 1500-1700 $\mathrm{h}$ and the body weight of each animal was recorded before decapitation. Cycling female rats were killed at the first estrous phase of the estrous cycle when cornified cells were visible in the vaginal smear in the 10th week of irisin/saline exposure. Thus, it was 

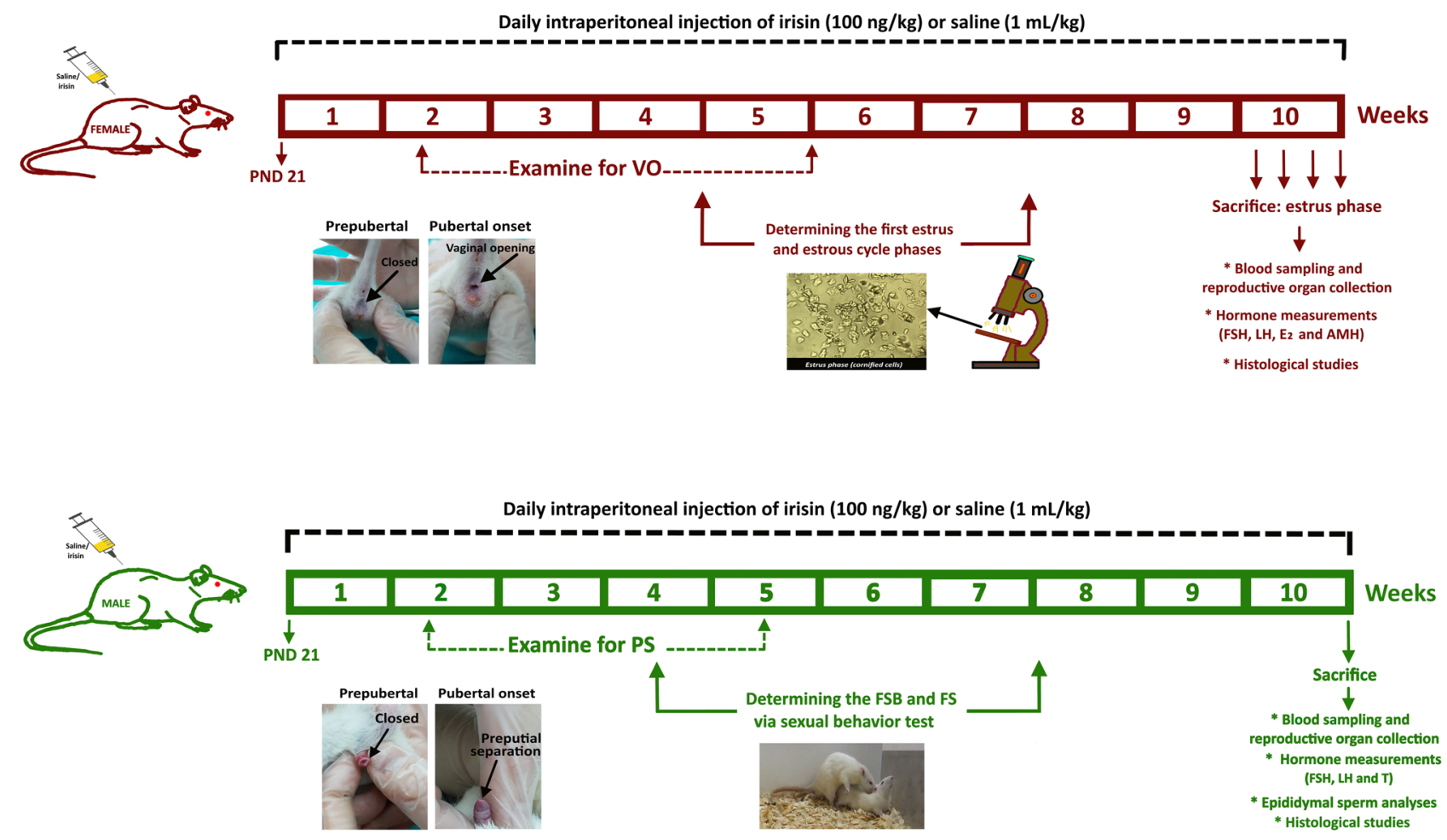

Figure 1 The flowchart of experimental works. PND: postnatal day; VO: vaginal opening; FSH: follicle-stimulating hormone; LH: luteinizing hormone; $\mathrm{E}_{2}$ : $17 \beta$-estradiol; $\mathrm{AMH}$ : anti-Müllerian hormone; PS: preputial separation; FBS: displaying time of first sexual behavior; FS: formation time of first sperm and $\mathrm{T}$ : testosterone.

taken into account that both control and irisin-treated female rats were in the same phase (estrous) for the collection of the blood samples and the ovaries and uterus tissues. In addition, all male rats were killed on the same day after 10 weeks of irisin/saline injection. Following decapitation, the trunk blood samples were collected, centrifuged $\left(4000 \mathrm{~g}\right.$ for $5 \mathrm{~min}$ at $+4^{\circ} \mathrm{C}$ ) and serum was obtained and frozen until hormonal assays. Additionally, uterus, ovaries, testes, epididymides and ventral prostate were quickly dissected out, cleared of adhering connective tissue and weighed as wet. Ovary and testis tissues were fixed in 10\% formaldehyde solution and Bouin's fixative for histological evaluation, respectively. In addition, the epididymis tissues weighed were taken for epididymal sperm analysis.

\section{Hormone measurements}

The serum concentrations of follicle-stimulating hormone (FSH), LH, $17 \beta$-estradiol $\left(E_{2}\right)$, anti-Müllerian hormone $(A M H)$ and TS were measured in duplicate by ELISA. Specific commercial ELISA kits for rats were used to quantify FSH (E-EL-R0391; Elabscience, USA), LH (ENZ-KIT107; Enzo Life Sciences, Switzerland), E 2 (ADI900-008; Enzo Life Sciences, Switzerland), AMH (E-EL-R0640; Elabscience, USA) and TS (CSB-E05100r; Cusabio, China) concentrations. The optical density was read at $405 \mathrm{~nm}$ for $\mathrm{E}_{2}$ plate and at $450 \mathrm{~nm}$ for $\mathrm{FSH}, \mathrm{LH}, \mathrm{AMH}$ or TS plates in a plate reader (Thermo Scientific). Sensitivity of the assays was $1.88 \mathrm{ng} /$ $\mathrm{mL}$ for $\mathrm{FSH}, 5.2 \mathrm{mIU} / \mathrm{mL}$ for $\mathrm{LH}, 28.5 \mathrm{pg} / \mathrm{mL}$ for $\mathrm{E}_{2}, 0.1 \mathrm{ng} / \mathrm{mL}$ for $\mathrm{AMH}$ and $<0.06 \mathrm{ng} / \mathrm{mL}$ for TS.

\section{Epididymal sperm analyses}

Analyses of epididymal sperm concentration, sperm motility and sperm morphology were carried out using the methods reported in the previous study (Yüce et al. 2013). Briefly, the epididymal sperm concentration in the right cauda epididymal tissue was determined with a hemocytometer. Freshly isolated left cauda epididymal tissue was used for the analysis of sperm motility. The percentage of forward progressive sperm motility was assessed visually using a light microscope with heated stage at $400 \times$ magnification. In order to determine the percentage of morphologically abnormal spermatozoa, first the slides were stained with eosin-nigrosin $(1.67 \%$ eosin, $10 \%$ nigrosin and $0.1 \mathrm{M}$ sodium citrate). The slides were then viewed under a light microscope at 400x magnification. A total of 300 spermatozoa were examined on each slide (3600 cells in each group), and the head, tail and total abnormality rates of spermatozoa were expressed as a percentage.

\section{Histological evaluation of ovaries and testicular tissues}

Formalin-fixed ovaries and Bouin's-fixed testes were dehydrated in a graded alcohol series and graded ethanol, respectively. After that, all tissues were embedded in paraffin wax. The ovaries were cut into $5-\mu \mathrm{m}$ sections and stained with hematoxylin and eosin (H\&E) and also Masson trichrome staining, while the testes were cut into 5-6 $\mu \mathrm{m}$ sections and stained with H\&E. All tissue sections were examined, evaluated and photographed in random order under blinded conditions 
using a Leica DM500 microscope (DFC295; Leica). In every section, randomly chosen 20 areas were examined and scored under 20× magnification.

Ovarian follicular reserve and fibrosis were evaluated by light microscopy. The follicles were histologically classified as primordial, primary, secondary, and Graaf and all follicular structures were counted in each section. The fibrosis was evaluated with Masson's trichrome staining and scored from 0 to 3 semi-quantitatively $(0=$ no fibrosis, $1=$ low fibrosis, 2 =intermediate fibrosis, 3 = severe fibrosis) (Artaş et al. 2018).

The histological findings in each section were scored semiquantitatively for the detection of testicular damage: none (0), mild (1), moderate (2) and severe (3). In the histomorphometric study, 200 round or nearly round cross sections of seminiferous tubule were randomly selected and analyzed for seminiferous tubule diameter and germinal epithelium height (Jewo et al. 2012).

\section{Statistical analysis}

Data are presented as the mean \pm S.D. A Shapiro-Wilk test was used to verify the normality of distribution of variables. Therefore, pubertal and sexual maturation, all the sperm characteristics, hormone levels, reproductive organ weights and histological findings were distributed normally. The unpaired Student's $t$-test was used to determine the differences between two groups in female and male. $P$-values less than 0.05 were accepted to indicate statistical significance.

\section{Results}

\section{The effects of chronic irisin administration on the timing of puberty in the rats}

The vaginal opening in female rats and preputial separation in male rats, external markers of puberty, were used to indicate pubertal onset from PND 30 (Korenbrot et al. 1977, Ojeda \& Urbanski 1994). Vaginal opening was significantly delayed in female irisin group (postnatal day $52.4 \pm 2.4$ ) when compared with the female control group (postnatal day $49.1 \pm 1.9, P<0.001$, Fig. $2 \mathrm{~A}$ ). The first vaginal opening day of control group was PND 46, whereas PND 49 in the irisin group. In addition, all female rats in the control group had complete canalization of the vagina on PND 52, while only $50 \%$ of female rats treated with irisin showed synchronized vaginal opening at the same age (Fig. 2A). However, the day of preputial separation of males was unaffected by irisin exposure (postnatal day 49 \pm 2 ) compared with male control rats (postnatal day $48.7 \pm 1.7$ ) (Fig. 2B). All animals in the irisin group and $91.67 \%$ of the animals in the control group completed preputial separation at PND 51. Overall, in the male control and irisin groups, preputial separation occurred between PND 46 and 52 and PND 45 and 51, respectively (Fig. 2B). Parallel to the time of puberty onset, pubertal weight was significantly higher in the female irisin group $(159.1 \pm 7.5 \mathrm{~g}$ vs $130.3 \pm 6.4 \mathrm{~g}$ for the female control group, $P<0.001$, Fig. 2C) and did not change in male rats treated with irisin $(170 \pm 14.4 \mathrm{~g}$ vs $165.9 \pm 10.9 \mathrm{~g}$ for the male control group, Fig. 2D).

\section{The effects of chronic irisin administration on first estrus and estrous cyclicity}

Beginning on the day of vaginal opening, the estrous cycle was examined by daily vaginal smear during 15 days (average 3 estrus cycles) for each animal, andthe age at first estrus was also determined during this experiment period (Marcondes et al. 2002). In addition to displaying delayed vaginal opening, first estrus was also significantly delayed in female irisin group (postnatal day $53.1 \pm 2.5$ vs $51 \pm 1.1$ for the female
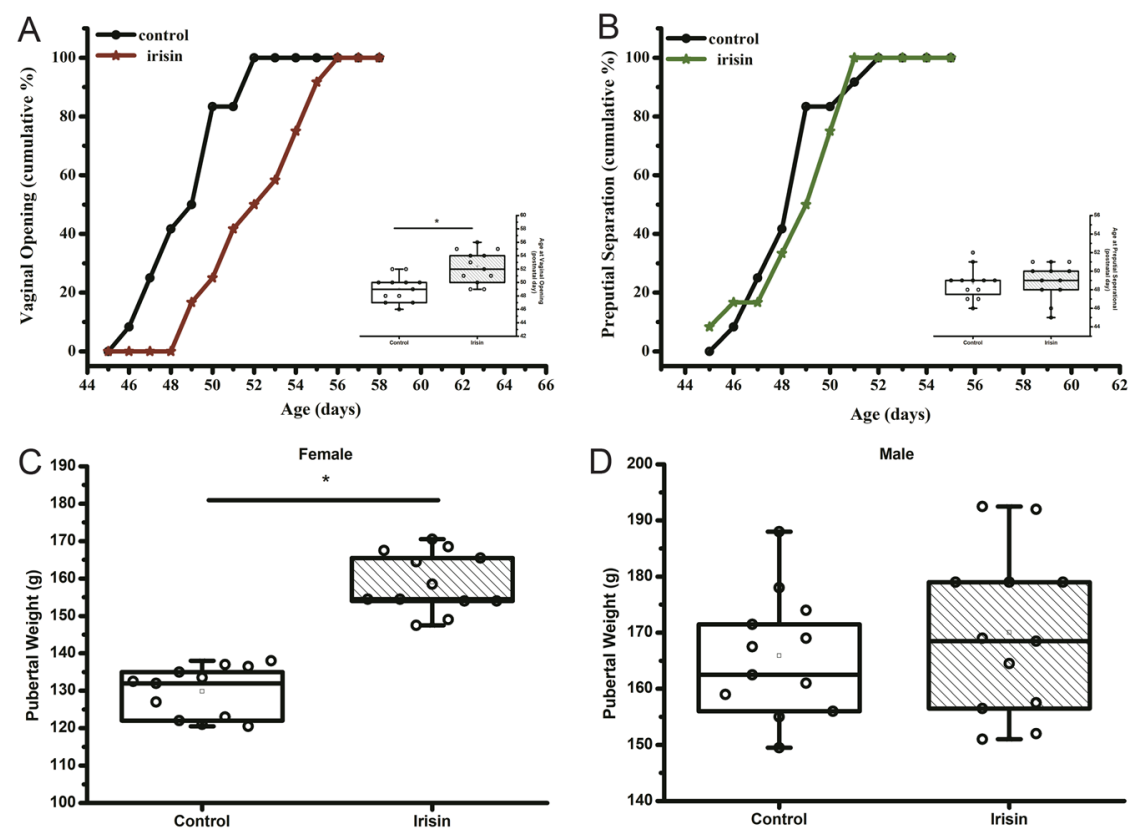

Figure 2 Effects of chronic irisin exposure on pubertal maturation in female and male rats. (A) Cumulative percentage of female rats exhibiting first vaginal opening. (B) Cumulative percentage of male rats displaying first preputial separation. (C and D) Pubertal weights of female and male rats. Each experimental group consisted of 12 animals. Data are given as mean \pm S.D. per group. ${ }^{*} P<0.001$ vs female control group (Student's $t$-test).

Reproduction (2020) 160 281-292 
control group, $P<0.05)$, both external markers of puberty onset. Distribution of the day of first estrus can be seen in Fig. 3A. Based on lavages, all irisin-treated rats displayed regular estrous cycles of $4-5$ days, and hence, the percentage of rats that achieve cyclicity as an adult was similar in control and irisin groups (100\%). Estrous cyclicity showed that there was no difference in the mean duration of the metestrus/diestrus, proestrus and estrus phases of irisin-treated rats compared with the control rats. Thus, the mean duration of one estrous cycle was not affected with irisin treatment (Fig. 3B).

\section{The effects of chronic irisin administration on sexual maturation in male rats}

After determining the preputial separation, the effects of exogenous irisin on sexual maturation of male rats (displaying time of first sexual behavior and formation time of first sperm) were assessed by daily sexual behavior tests. When compared to the male control group, there was no significant change in the displaying time of first sexual behavior in male irisin group (postnatal day $64.8 \pm 2.2$ and $64.9 \pm 1.6$, respectively, Fig. 3 C). In the male irisin group, the formation time of first sperm was significantly earlier compared to the male control group (postnatal day $66.2 \pm 1.5$ and $68.9 \pm 1.3$, respectively, $P<0.001$, Fig. 3D).

\section{The effects of chronic irisin administration on reproductive organ weights in the rats}

The ovaries, uterus, testes, epididymides and ventral prostate weights were calculated for $100 \mathrm{~g}$ body weight (BW) in each group. Irisin treatment did not affect the weights of the ovaries $(60.7 \pm 6.6 \mathrm{mg} / 100 \mathrm{~g}$ BW vs
$64 \pm 4 \mathrm{mg} / 100 \mathrm{~g} \mathrm{BW}$ for the female control group, $P>0.05)$ and uterus $(207 \pm 26.5 \mathrm{mg} / 100 \mathrm{~g}$ BW vs $196.2 \pm 28.4 \mathrm{mg} / 100 \mathrm{~g}$ BW for the female control group, $P>0.05)$ in comparison to the female control group. No statistically significant differences were observed between control and irisin groups in terms of testes $(876.4 \pm 96.7 \mathrm{mg} / 100 \mathrm{~g}$ BW and $843 \pm 69.5$ $\mathrm{mg} / 100 \mathrm{~g} B W$, respectively, $P>0.05)$ and epididymides $(313.7 \pm 27.8 \mathrm{mg} / 100 \mathrm{~g} \mathrm{BW}$ and $302.1 \pm 27.4 \mathrm{mg} / 100$ g BW, respectively, $P>0.05)$ weights. However, irisin exposure caused a significant decrease in weights of ventral prostate when compared to the male control group $(105.1 \pm 13.8 \mathrm{mg} / 100 \mathrm{~g} \mathrm{BW}$ vs $122 \pm 12.8 \mathrm{mg} / 100$ g BW for the male control group, $P<0.05$, Fig. 4 A).

\section{The effects of chronic irisin administration on sperm concentration, motility and morphology}

To assess whether chronic irisin exposure affects the sperm characteristics, we performed epididymal sperm analyses at the end of the experiment (Yüce et al. 2013). It was determined that chronic irisin administration significantly increased the sperm concentration when compared to the male control group $(171.2 \pm 27.7$ million/right cauda epididymis and $145.6 \pm 21.4 \mathrm{million} /$ right cauda epididymis, respectively, $P<0.05$, Fig. 4B). However, there was no statistically significant difference in sperm motility and also head, tail and total abnormal sperm rates in comparison to the male control group (Fig. 4C and D).

\section{The effects of chronic irisin administration on serum levels of reproductive hormones in the rats}

The effects of chronic exposure to irisin in activating the reproductive axis were also assessed by hormonal
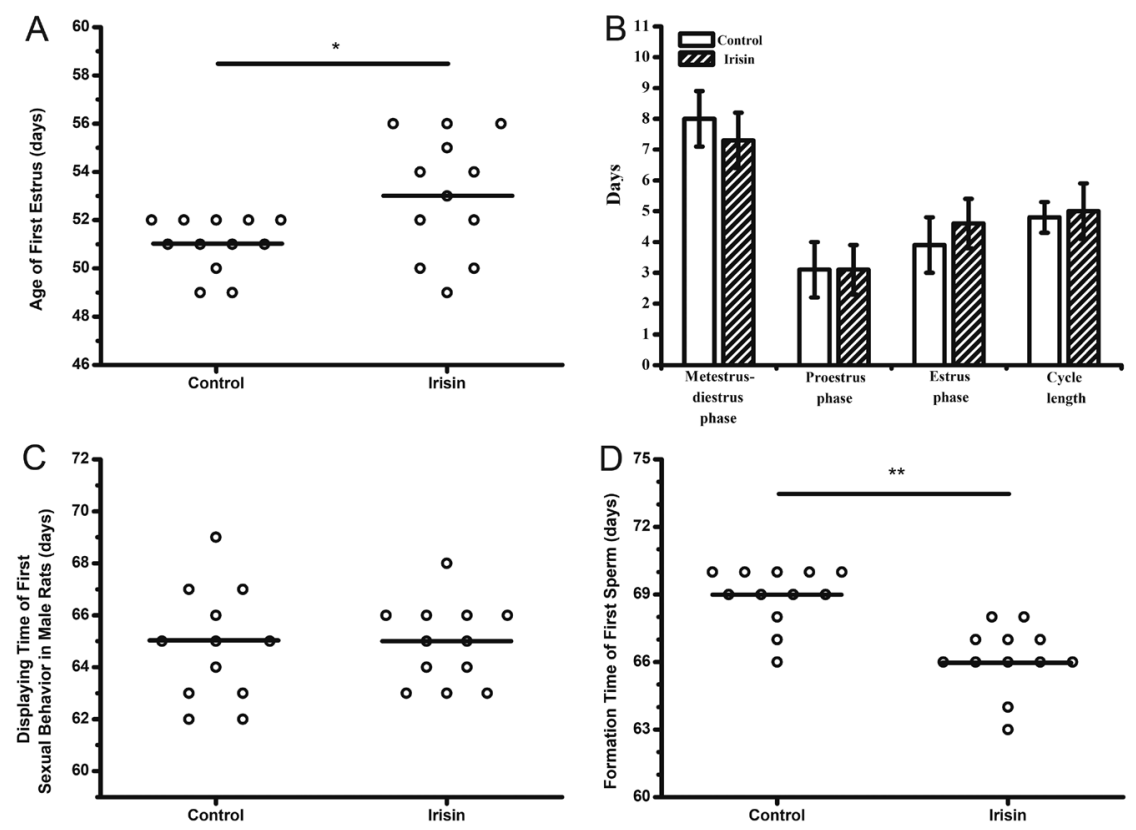

Figure 3 Effects of chronic irisin exposure on first estrus and estrous cycle in female rats and displaying time of first sexual behavior and formation time of first sperm in male rats. (A) Ages at first estrus. (B) The number of days spent in each estrous cycle stage and length of estrus cycle. (C and D) Time course of day of displaying time of first sexual behavior and formation time of first sperm. Each experimental group consisted of 12 animals. Data are given as mean \pm S.D. per group. $* P<0.05$ vs female control group and ${ }^{* *} P<0.001$ vs male control group (Student's t-test). 

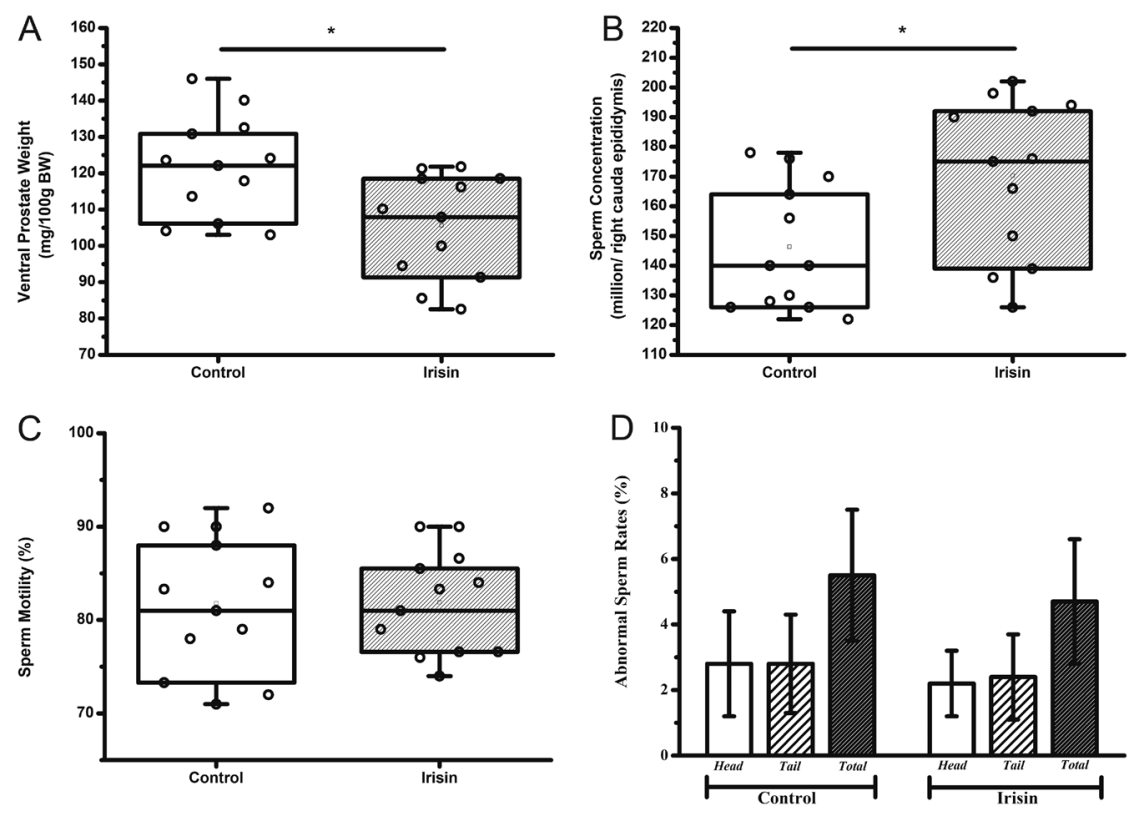

Figure 4 Effects of chronic irisin exposure on
ventral prostate weights and epididymal sperm
characteristics. (A) Ventral prostate weights.
(B, C and D) Epididymal sperm concentration,
sperm motility and abnormal sperm rate. Each
experimental group consisted of 12 animals.
Data are given as mean \pm s.D. per group.
$* P<0.05$ vs male control group (Student's
$t$-test). BW: body weight.

responses, including $\mathrm{LH}, \mathrm{FSH}, \mathrm{E}_{2}, \mathrm{AMH}$ and TS levels. In the female rats, chronic irisin exposure significantly increased serum LH levels $(375.1 \pm 41.9 \mathrm{mIU} / \mathrm{mL}$ vs $302.6 \pm 38.6 \mathrm{mIU} / \mathrm{mL}$ compared to the female control group, $P<0.01$, Fig. $5 \mathrm{~A}$ ), while it significantly reduced serum FSH levels $(114.6 \pm 40.6 \mathrm{ng} / \mathrm{mL}$ vs $180.7 \pm 45 \mathrm{ng} /$ $\mathrm{mL}$ compared to the female control group, $P<0.01$, Fig. $5 B)$. Also, the levels of serum $E_{2}$ showed a significant increase in the irisin-treated rats compared to the control rats $(1706.6 \pm 453.6 \mathrm{pg} / \mathrm{mL}$ and $1250.2 \pm 269.6 \mathrm{pg} / \mathrm{mL}$, respectively, $P<0.01$, Fig. $5 \mathrm{C}$ ). On the other hand, no alteration in serum AMH levels was detected between irisin and control group $(3.9 \pm 0.5 \mathrm{ng} / \mathrm{mL}$ and $3.8 \pm 0.4$ $\mathrm{ng} / \mathrm{mL}$, respectively, Fig. 5D).

In male rats, chronic administration of irisin significantly increased serum LH levels when compared to control group $(\mathrm{mlU} / \mathrm{mL}$; control group: 293.6 \pm 41 and irisin group: $356 \pm 37.1, P<0.01$, Fig. 5E), but did not affect the serum FSH levels $(95.5 \pm 33.5 \mathrm{ng} /$ $\mathrm{mL}$ vs $106.4 \pm 20.3 \mathrm{ng} / \mathrm{mL}$ for the male control rats, Fig. 5F). Furthermore, serum TS levels in irisin group was significantly increased compared to control group $(15.6 \pm 5.3 \mathrm{ng} / \mathrm{mL}$ and $10 \pm 2.5 \mathrm{ng} / \mathrm{mL}$, respectively, $P<0.05$, Fig. 5G).

\section{The effects of chronic irisin administration on histology of ovary and testis tissues}

Finally, to investigate the general effects of chronic irisin exposure on ovarian and testicular morphology, we carried out histological analysis (Jewo et al. 2012, Artaş et al. 2018). The general ovarian histological structures of irisin group were similar to the control group. Ovarian sections from control and irisin groups showed a cortex consisting of primordial, primary, secondary and tertiary follicles, and corpus luteum. In addition, granulosa and theca cells at different stages of follicular development had regular histological structure in the control and irisin groups (Fig. 6). Morphometric analysis during the estrous phase exhibited that irisin-treated ovaries showed no consequential change in the mean number of different types of follicles: primordial, secondary, tertiary follicles and corpus luteum. However, there was a significant decline in the mean number of primary follicles when compared to control group $(2.4 \pm 0.9$ and $8.5 \pm 2$, respectively, $P<0.001$, Table 1 ). Regarding fibrosis, a significant increase was observed in the irisin group on the ovarian tissues compared to the control group $(1.83 \pm 0.3$ and $0.5 \pm 0.3$, respectively, $P<0.05$, Table 1 ).

Normal seminiferous tubule morphology was observed in the control group, whereas there were significant histological changes in male rats treated with irisin (Fig. 7). Chronic irisin treatment significantly increased germ cells spilled into the lumen of the seminiferous tubules $(0.88 \pm 0.2$ vs $0.21 \pm 0.1$ compared to the male control group, $P^{<} 0.01$ ) and detachment of the basement membrane of seminiferous tubules was observed $(0.54 \pm 0.2$ vs $0.13 \pm 0.1$ compared to the male control group, $P<0.05$, Table 2). The histomorphometric study of seminiferous tubules showed that seminiferous tubule diameter increased in irisin group when compared to control group $(302.2 \pm 3.5 \mu \mathrm{m}$ and $284.8 \pm 3.7 \mu \mathrm{m}$, respectively, $P<0.001$, Table 2 ). However, chronic exposure to irisin led to a significant decrease in the germinal epithelium height $(79.1 \pm 1 \mu \mathrm{m}$ vs $82.5 \pm 1 \mu \mathrm{m}$ for the male control group, $P<0.05$, Table 2 ).

\section{Discussion}

In the present study, we evaluated the effects of chronic irisin exposure on two relevant reproductive states, 

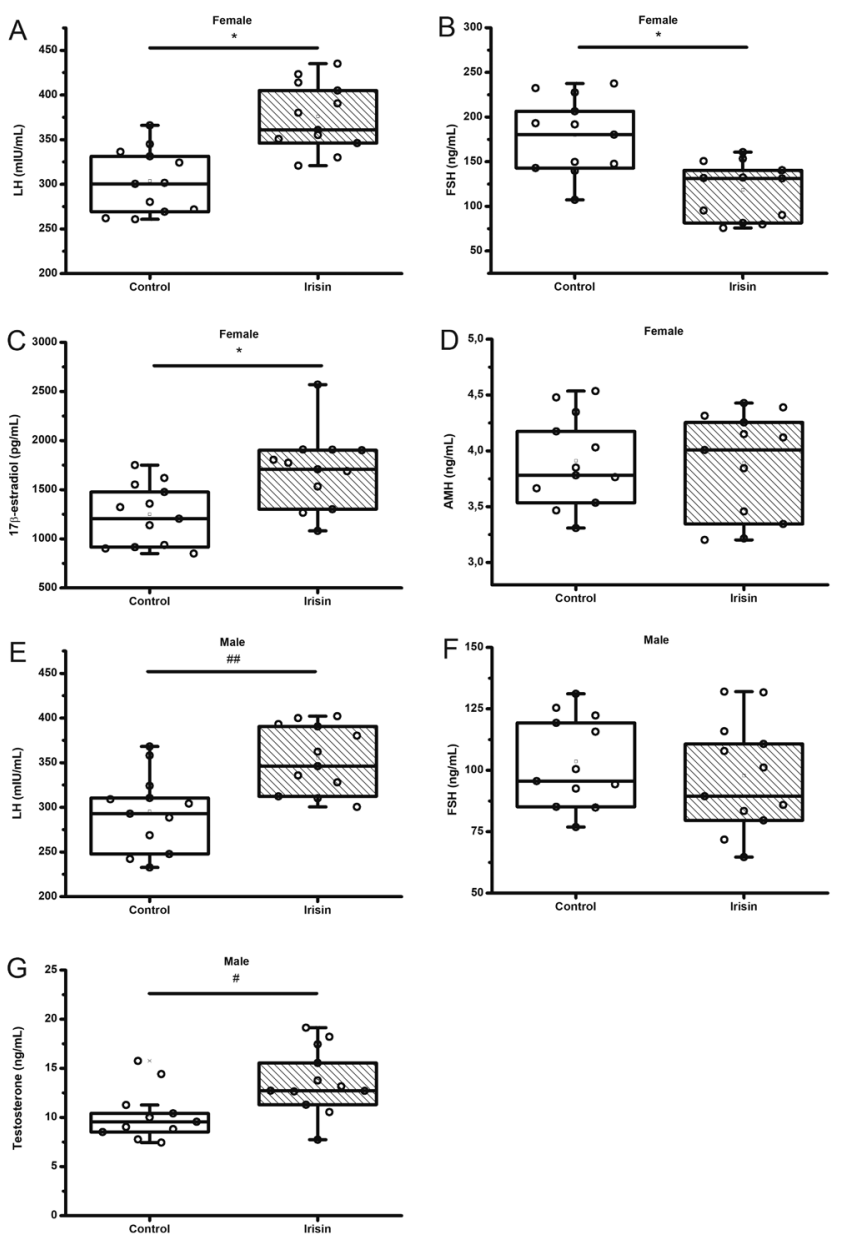

Figure 5 Effects of chronic irisin exposure on serum reproductive hormone levels in rats. (A, B, C and D) Serum LH, FSH, 17 $\beta$-estradiol and $\mathrm{AMH}$ levels in female rats. (E, F and G) Serum LH, FSH and testosterone levels in male rats. Each experimental group consisted of 12 animals. Data are given as mean \pm S.D. per group. ${ }^{*} P<0.01$ vs female control group and ${ }^{\sharp} P<0.05$ and ${ }^{\# \#} P<0.01$ vs male control group (Student's $t$-test). LH: luteinizing hormone; FSH: folliclestimulating hormone; $\mathrm{AMH}$ : anti-Müllerian hormone. pubertal maturation and reproductive function, in female and male rats. We provide here the first evidence that irisin administration can have opposing genderdependent effects both on the puberty onset and also on the reproductive function in rats. Chronic exposure to irisin lead to delayed onset of puberty and delayed first estrus in female rats. In addition, chronic irisin administration caused hormonal changes by decreasing the serum FSH levels and increasing the serum LH and $E_{2}$ levels. Parallel with these changes, decrease in primary follicles and increase in fibrosis were detected in ovarian tissue of irisin-treated rats. Conversely, although daily i.p. administration of irisin to prepubertal male rats did not affect the timing of puberty onset, the formation time of first sperm was earlier. Moreover, it was found that chronic irisin exposure induced major changes in androgenic markers such as increased sperm concentration and serum LH and TS levels, but adversely affected the testicular tissue.

\section{Chronic irisin administration delayed pubertal development in female rats}

In our study, the administration of irisin resulted in a significant delay in the age of vaginal opening in female rats. However, the average age of vaginal opening (PND 49 ) in the control group was found to be later than in previous studies (around PND 32) (Kim et al. 2002, Shiorta et al. 2012). Vaginal opening in female rats may depend on colony-specific differences, taking place between PND 46-52 in the present study. And in our previous study, similar results were noticed on the day of the vaginal opening (around PND 49) in SpragueDawley female rats (Canpolat et al. 2016).

In the literature, there are few clinical studies evaluating the role of irisin in pubertal maturation in boys and girls. Jang et al. (2017) had previously shown that serum irisin levels did not differ among pubertal stages (pre-pubertal, pubertal and post-pubertal

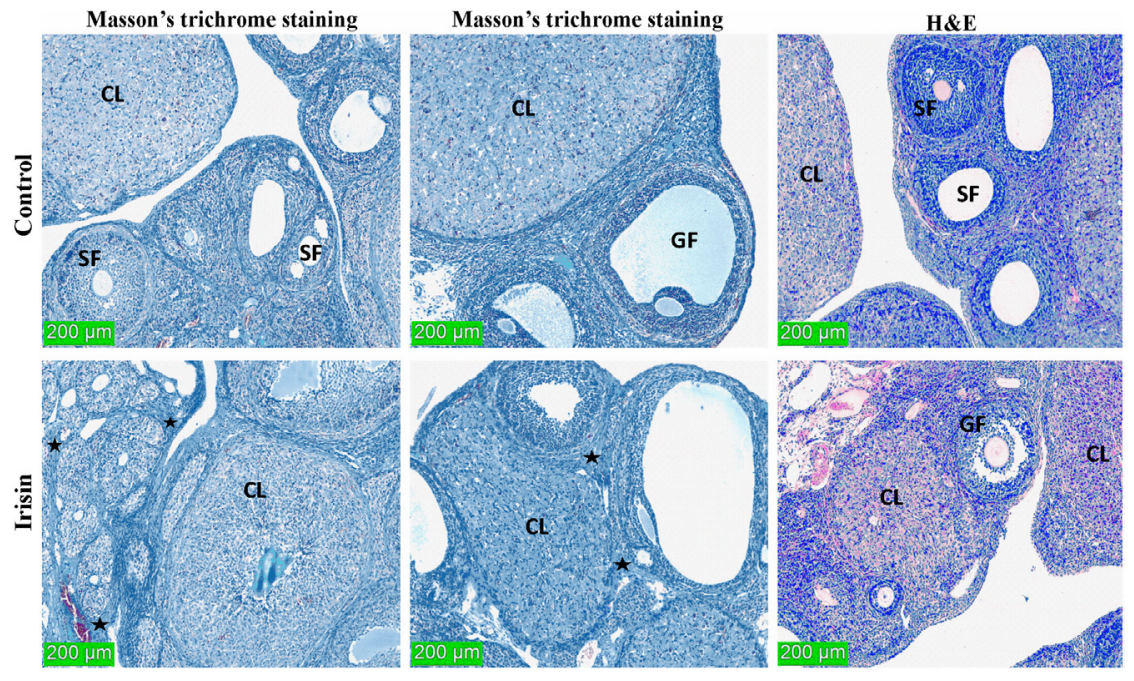

Figure 6 Histological appearance of ovaries in the control and irisin groups. Histological sections of ovary were stained with hematoxylin and eosin (H\&E) and Masson trichrome staining. CL: corpus luteum; SF: secondary follicle; GF: graaf follicle; Black star: ovarian fibrosis in the parenchyma. 
Table 1 The histopathological score of fibrosis and number of ovarian follicles in female control and irisin groups.

\begin{tabular}{llc}
\hline Variable & Control & Irisin \\
\hline Fibrosis & $0.5 \pm 0.3$ & $1.83 \pm 0.3^{*}$ \\
Primordial follicle & $6.6 \pm 1.3$ & $6 \pm 1$ \\
Primary follicle & $8.5 \pm 2$ & $2.4 \pm 0.9^{* *}$ \\
Secondary follicle & $8.4 \pm 3.3$ & $5.5 \pm 1$ \\
Tertiary follicle & $1.4 \pm 0.6$ & $0.8 \pm 0.5$ \\
Corpus luteum & $9.6 \pm 2.4$ & $9.4 \pm 3.1$ \\
\hline
\end{tabular}

Values are given as mean \pm S.D.

$* P^{<} 0.05$ and $* * P^{<} 0.001$; when compared to female control group.

stage) or menarche in normal-weight girls (Jang et al. 2017). Unlike normal-weight children, another study conducted in obese children of both sexes showed that puberty was associated with an increase in the levels of irisin (Reinehr et al. 2015). On the other hand, Blüher et al. (2014) suggested that the level of irisin were independent of age, gender, body weight and pubertal stage in obese children (Blüher et al. 2014).

Although the effects of irisin on pubertal maturation remains controversial, these discordant findings across studies may be explained by the presence of various factors such as genetic, socioeconomic conditions, nutrition and environmental factors, which play roles in the timing of puberty in human (Louis et al. 2008). Therefore, in the present study, animal model was used to clarify the main role of irisin hormone in pubertal processes without the confounding factors mentioned previously. To the best of our knowledge, our data provide the first evidence that irisin exposure may have different effects on reproductive axis at puberty depending on gender in a rat model.
For the first time in this study, it was revealed that the chronic administration of irisin, which is an exercise hormone, caused delayed puberty and delayed age of first estrus in female rats. It is already known that long-term or high-intensity exercise causes impairment of normal reproductive functions in female athletes. Increases in physical exertion cause hormonal imbalances by disturbing the balance of the HPG axis. Depending on this, delayed puberty, delayed menstruation and menstruation disorders occur (Leal-Cerro et al. 2003, Enea et al. 2011, Witkoś \& Wróbel 2019). However, the action mechanism of chronic or intensive exercise on reproductive function is still not known. As a result, we speculate that irisin hormone may play roles in the negative effects of intense or long-term exercise on the female reproductive system.

In addition, it was also reported in studies conducted with female athletes that leptin release is inhibited or decreased with intense exercise (Leal-Cerro et al. 2003, Witkoś \& Wróbel 2019). Leptin plays important roles in the regulation of fertility and acts as a stimulant especially in the transition to puberty. A critical leptin level is necessary for the onset and continuity of puberty and menstruation (Martos-Moreno et al. 2010). In the previous study of our group, we observed that the persistent s.c. perfusion of irisin significantly decreased serum leptin levels in female rats (Ozcan et al. 2020). Overall, it was assumed that chronic irisin exposure may have decreased serum leptin levels in female rats, and consequently, female reproductive disorders occurred in the present study. As a whole, our results suggest that chronic administration of irisin may imitate the effects of long-term or intensive exercise training in females.

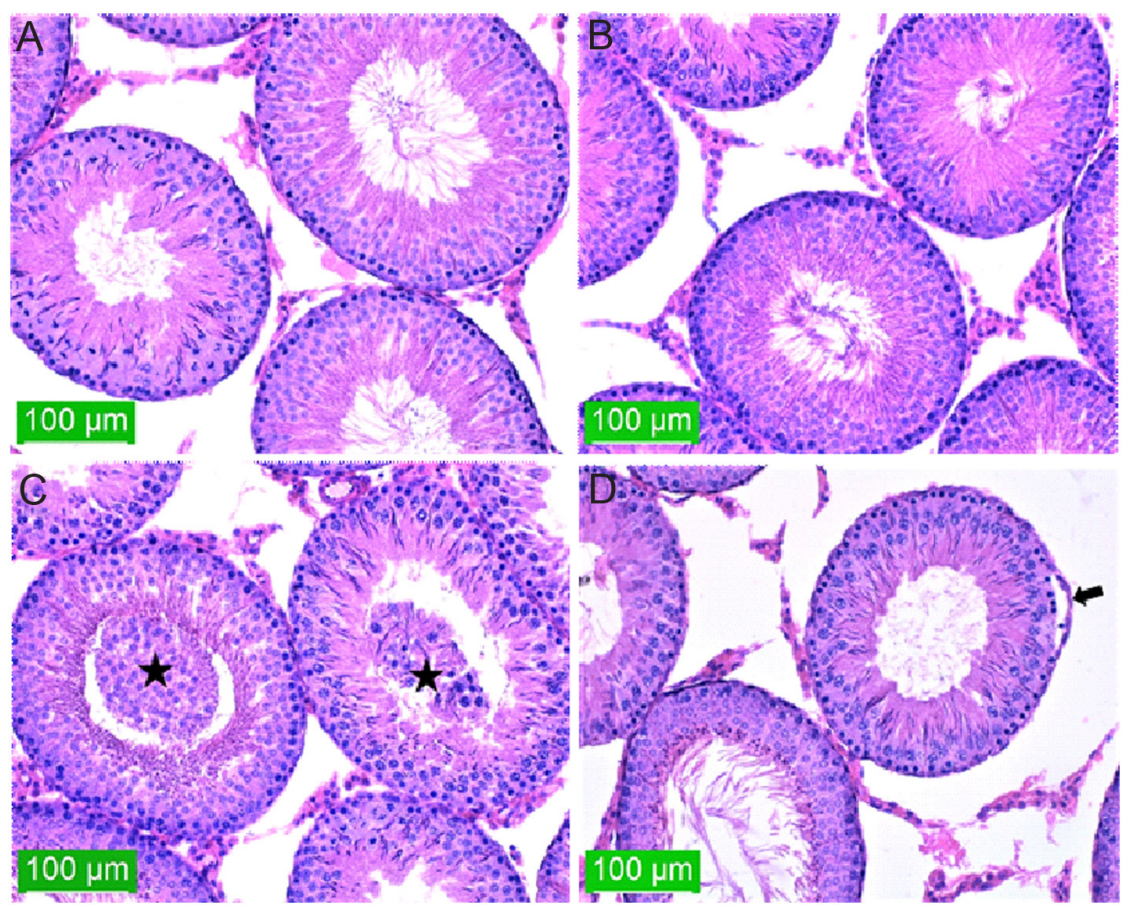

Figure 7 Light microscopy of testicular tissue in control and irisin groups. (A and B) In control group, normal testicular structure was observed; germinal epithelium, Sertoli cells, basement membrane and interstitial space were normal. (C and D) In irisin group, germ cells spilled into the lumen of the seminiferous tubules (star) and detachment of the basement membrane of seminiferous tubules (arrow) was observed. 
Table 2 Semi-quantitative histology-based analyses (histological scores and histometric data) from testicular tissues in control and irisin groups.

\begin{tabular}{lcc}
\hline Variable & Control & Irisin \\
\hline Germ cells spilled into the lumen of the seminiferous tubules & $0.21 \pm 0.1$ & $0.88 \pm 0.2^{* *}$ \\
Detachment of the basement membrane of seminiferous tubules & $0.13 \pm 0.1$ & $0.54 \pm 0.2^{*}$ \\
Seminiferous tubule diameter $(\mu \mathrm{m})$ & $284.8 \pm 3.7$ & $302.2 \pm 3.5^{* * *}$ \\
Germinal epithelium height $(\mu \mathrm{m})$ & $82.5 \pm 1$ & $79.1 \pm 1^{*}$ \\
\hline
\end{tabular}

Data shown are mean \pm S.D.

$* P<0.05,{ }^{* *} P<0.01$ and ${ }^{* * *} P<0.001$; when compared to male control group.

\section{Chronic irisin administration altered reproductive endocrine function in female rats}

Determining the secretion of gonadotropin and sex steroid hormones might be an important parameter to evaluate the effects of irisin on reproductive endocrine function. Therefore, in the present study, chronic administration of female rats with irisin caused major hormonal changes in $\mathrm{FSH}, \mathrm{LH}$ and $\mathrm{E}_{2}$ secretion. Poretsky et al. (2017) showed that the administration of irisin in the murine pituitary cell line stimulates the LH production (Poretsky et al. 2017). Similarly, it was reported that irisin stimulates gonadotropin gene expression in tilapia pituitary cells (Jiang et al. 2017). Parallel to the previously mentioned studies, it was also found in the present study that the administration of chronic irisin increased serum $\mathrm{LH}$ concentration in female rats. There are studies in the literature showing that irisin increases or decreases FSH levels (Jiang et al. 2017, Tekin et al. 2019). It was found in this study that the administration of chronic irisin reduced the serum FSH levels at significant levels in female rats. We report here for the first time that chronic irisin exposure modulated the $\mathrm{FSH}$ and $\mathrm{LH}$ secretion in female rats. These imbalances in both $\mathrm{FSH}$ and $\mathrm{LH}$ secretion can reflect neuroendocrine abnormalities, which is associated with various female fertility disorders.

Another noteworthy finding of this study was the increase in serum $E_{2}$ levels depending on chronic irisin administration to female rats. In an in vitro study, it was reported that irisin increased the $E_{2}$ production in the primary culture of human granulosa cells; however, when irisin is administrated with insulin, the simulant effect of irisin on $E_{2}$ production was eliminated (Poretsky et al. 2017). As a result, the importance of this study is emerging especially in determining the physiological effect of irisin on ovarian function because irisin interacts with insulin as well as gonadotropins and various autocrine/paracrine factors in vivo environment. For this reason, chronic irisin administration may increase serum $\mathrm{E}_{2}$ levels by changes in $\mathrm{FSH}$ and $\mathrm{LH}$ levels or by directly affecting the ovaries.

\section{Chronic irisin administration caused pathological changes in ovarian tissues}

In the present study, the decrease in the number of primary follicles because of chronic irisin administration might be associated with decreased serum FSH levels.
Similarly, it has previously been reported that FSH may affect the development of primary follicles (Tanaka et al. 2001). In mammals, FSH is an important circulatory hormone stimulating post-puberty follicular growth and development, and a decrease or no increase in FSH levels causes a failure in follicular growth and, depending on this, a decrease in ovarian reserve (Macklon \& Fauser 2001, Doherty et al. 2002). Overall, our data indicate that changes in gonadotropin secretion and ovarian steroidogenesis and folliculogenesis due to chronic irisin administration may lead to adverse effects on female fertility.

Another important pathological change, which is caused by irisin hormone in ovarian tissue, is fibrosis. The increased fibrosis in the ovarium tissue of irisin-treated rats may cause a decrease in primary follicle count. And it can be speculated that this may cause structural damage in the ovarium tissue. In addition to this, these morphological findings (i.e. the decrease in the number of primary follicles and increase in fibrosis) support that irisin may have effects on the HPG axis in females.

In the present study, however, we found that chronic irisin exposure did not affect the serum AMH levels in females despite the pathological changes in ovarian tissues. In previous studies, in addition to determining the number of follicles in histological examinations, the measurement of serum AMH levels is among the recommended methods for evaluating ovarian reserve (Benian et al. 2013). In rodents, especially the circulating serum AMH level is a good predictor of ovarian reserve. $\mathrm{AMH}$ expression starts in the granulosa cells of primary follicles, and the highest expression is detected in the granulosa cells of small antral follicles with preantral. The decrease in $\mathrm{AMH}$ level is responsible for the decrease in the number of growing follicles (Visser et al. 2012, La Marca et al. 2013). According to the results of the present study, the chronic irisin administration decreased only the number of primary follicles, and it is seen that this decrease did not affect serum AMH levels. Furthermore, the fact that the serum AMH levels were not changed reflects that the chronic irisin administration may not have affected functional granulosa cells.

\section{Chronic irisin administration did not affect pubertal development in male rats}

In the present study, it was determined that the chronic irisin administration did not affect the transition to 
puberty and pubertal weight in male rats. For this reason, it may be considered that the peripheral irisin administration for the first 4-5 weeks does not have an effect on the HPG axis in male rats. However, when the fact that the ongoing and approximately 10-week irisin administration increased the TS release is considered, it is considered that the duration of irisin administration has different effects on the reproductive system.

In a recent study, it was suggested that intracerebroventricular (i.c.v.) irisin administration may have an inhibitory effect on the HPG axis in adult male rats (Tekin et al. 2019). The contradiction between the previously mentioned study and the data obtained in this study can be explained by the dose, method of administration or the period of the irisin administration.

\section{Chronic irisin administration displayed androgenic activity in male rats}

The administration of chronic irisin has advanced the first sperm formation time and significantly increased the sperm concentration without causing significant changes in sperm motility and abnormal sperm ratio. Thus, chronic exposure to irisin may have advanced the initiation of spermatogenesis in male rats in the postpubertal period. A certain androgen concentration is needed for the onset and continuity of spermatogenesis, and it is already known that increased TS levels show a positive correlation with the increase in the number of mature sperms (Bawazir 2010, Chauhan \& Dixit 2010). In the present study, it was found that the chronic irisin administration increased the LH and TS concentrations at significant levels in male rats without causing significant increases in FSH. LH stimulates TS production in Leydig cells, and TS stimulates spermatogenesis indirectly by affecting the Sertoli cells (Parandin et al. 2012). In this study, the significant increase in the LH concentration in male rats treated with irisin may cause increased TS release in Leydig cells. Therefore, this may be the indication that the irisin hormone has a stimulating effect on the hypothalamic-pituitary axis of the male rats.

Both TS and FSH have important functions in spermatogenesis. However, especially FSH plays a key role in adult spermatogenic potential and in maintaining spermatogonial development (Chauhan \& Dixit 2010). In this study, considering that irisin significantly increased the diameter of the seminiferous tubule, the increase in spermatogenesis may be related to the fact that the irisin stimulates seminiferous tubules directly albeit the unchanged FSH levels. In addition, it may also be speculated that increased TS levels depending on the irisin administration may indirectly increase sperm concentration.

Testosterone, $\mathrm{LH}$ and FSH are the hormonal markers of androgenicity, and in particular, TS is the major index of androgenicity (Yakubu et al. 2008). For this reason, it may be suggested that irisin hormone may have androgenic potential which enhances normal testicular function in male rats. As a result, it was demonstrated for the first time in this study that chronic irisin administration increased fertility parameters in male rats (sperm concentration, TS and LH concentration and seminiferous tubule diameter). Therefore, we speculated that irisin may use as a remarkable agent to treat infertility in males.

\section{Chronic irisin administration caused histological alterations in testis tissues of rats}

An interesting outcome of this study is the emergence of histological changes in testicular tissue in the irisin group. We showed that chronic irisin administration causes anomalies in seminiferous tubules (germ cells spilled into the lumen of the seminiferous tubules and detachment of the basement membrane of seminiferous tubules) and decreases in germinal epithelium height. Similarly, Tekin et al. (2019) found that the irisin administration for 7 days i.c.v. caused mild histological changes in seminiferous tubules in rats and reduced the germinal epithelium thickness (Tekin et al. 2019). Furthermore, unlike the previously mentioned study, it was found in the present study that the chronic irisin administration significantly increased the diameter of the seminiferous tubule. In this study, we speculate that the changes in the serum reproductive hormone levels (LH and TS levels) due to chronic irisin administration may be responsible for these histological changes in testicular tissue. For this reason, detailed studies are needed to reveal the androgenic activity of irisin as well as its effects on testicular tissue.

In addition, there was a decrease in ventral prostate weight after chronic irisin administration in the present study. Some in vitro and animal studies indicate that exercise could have positive effects on prostate health (Tymchuk et al. 2001, Esser et al. 2009, Guéritat et al. 2014). Shokri et al. (2010) found that chronic exercise combined with chronic anabolic-androgenic steroid use decreased the relative ventral prostate weight in rats (Shokri et al. 2010). The more potent androgen to support the growth of the prostate is dihydrotestosterone. Dihydrotestosterone is produced from testosterone by the enzyme $5 \alpha$-reductase in the prostate gland (Gossell-Williams et al. 2006). Therefore, the increase in serum testosterone levels with the simultaneous decrease in prostate weight suggests further research to elucidate the effects of irisin on androgen receptors and cellular mechanisms, especially the activity of the $5 \alpha$-reductase, involved in changes in the prostate gland. As a result, although the precise mechanisms remain unknown, the results of this study suggest that the effects of exercise on the prostate gland may be through irisin hormone. 


\section{Conclusion}

As a result, it was revealed in the present study that the chronic irisin administration had different effects on pubertal maturation and reproductive system in male and female rats. It was determined that chronic irisin administration delayed pubertal maturation and caused hormonal and pathological changes in the reproductive system in female rats. For this reason, these results suggest that the irisin hormone may play roles in the underlying mechanism of disorders in the reproductive system because of exercise in female athletes. In male rats, on the other hand, it was determined that irisin administration did not affect pubertal maturation but caused increases in androgenic activity. The results of this study show that the irisin hormone may play roles in the neuroendocrine control of the reproductive axis. Further studies are needed to determine the mechanisms that are involved in these changes that occur with the administration of irisin and to investigate whether fertility is affected by irisin administration.

\section{Declaration of interest}

The authors declare that there is no conflict of interest that could be perceived as prejudicing the impartiality of the research reported.

\section{Funding}

This work was supported by The Scientific and Technological Research Council of Turkey (TUBITAK, Project No: 118S519).

\section{Author contribution statement}

S $\mathrm{C}$ designed and supervised the study. $\mathrm{N} \mathrm{U}, \mathrm{A} Y$, and $\mathrm{O} B$ conducted all animal experiments. N K T performed the histological analysis. S O K and G T performed the epididymal sperm analyses. F G B conducted all hormone measurements. $\mathrm{S} \mathrm{C}$ and M O contributed to data analysis. S C and M O wrote the manuscript, and all authors approved the final manuscript.

\section{References}

Allouh MZ 2015 Effects of swimming activity on the copulatory behavior of sexually active male rats. International Journal of Impotence Research 27 113-117. (https://doi.org/10.1038/ijir.2014.42)

Anastasilakis AD, Polyzos SA, Saridakis ZG, Kynigopoulos G, Skouvaklidou EC, Molyvas D, Vasiloglou MF, Apostolou A, Karagiozoglou-Lampoudi T, Siopi A et al. 2014 Circulating irisin in healthy, young individuals: day-night rhythm, effects of food intake and exercise, and associations with gender, physical activity, diet, and body composition. Journal of Clinical Endocrinology and Metabolism 99 3247-3255. (https://doi.org/10.1210/jc.2014-1367)

Artaş G, Pala Ş, Kuloğlu T, Atilgan R, Yavuzkir Ş \& Akyol A 2018 The effects of sclerotherapy with $5 \%$ trichloroacetic acid on the cyst diameter and ovarian tissue in the rat ovarian cyst model. Journal of Obstetrics and Gynaecology 38 686-692. (https://doi.org/10.1080/01443615.2017.13 99991)
Aydin S, Kuloglu T, Aydin S, Kalayci M, Yilmaz M, Cakmak T, Albayrak S, Gungor S, Colakoglu N \& Ozercan IH 2014 A comprehensive immunohistochemical examination of the distribution of the fat-burning protein irisin in biological tissues. Peptides 61 130-136. (https://doi. org/10.1016/j.peptides.2014.09.014)

Bawazir AE 2010 Investigations on the chronic effect of Talbina (Barly water) on hormone (cortisol and testosterone), reproductive system and some neurotransmitter. American-Eurasian Journal of Scientific Research 5 134-142.

Benian A, Guralp O, Uzun DD, Okyar A \& Sahmay S 2013 The effect of repeated administration of methotrexate (MTX) on rat ovary: measurement of serum antiMullerian hormone $(\mathrm{AMH})$ levels. Gynecological Endocrinology 29 226-229. (https://doi.org/10.3109/09 513590.2012.738725)

Blüher S, Panagiotou G, Petroff D, Markert J, Wagner A, Klemm T, Filippaios A, Keller A \& Mantzoros CS 2014 Effects of a 1-year exercise and lifestyle intervention on irisin, adipokines, and inflammatory markers in obese children. Obesity 22 1701-1708. (https://doi.org/10.1002/ oby.20739)

Boström P, Wu J, Jedrychowski MP, Korde A, Ye L, Lo JC, Rasbach KA, Boström EA, Choi JH, Long JZ et al. 2012 A PGC1- $\alpha$-dependent myokine that drives brown-fat-like development of white fat and thermogenesis. Nature 481 463-468. (https://doi.org/10.1038/nature10777)

Canpolat S, Ulker N, Yardimci A, Bulmus O, Ozdemir G, Sahin Z, Ercan Z, Serhatlioglu I, Kacar E, Ozcan M et al. 2016 Studies on the reproductive effects of chronic treatment with agomelatine in the rat. European Journal of Pharmacology 770 33-39. (https://doi.org/10.1016/j. ejphar.2015.11.054)

Chauhan NS \& Dixit VK 2010 Effects of Bryonia laciniosa seeds on sexual behaviour of male rats. International Journal of Impotence Research 22 190-195. (https://doi.org/10.1038/ijir.2009.62)

Doherty E, Pakarinen P, Tiitinen A, Kiilavuori A, Huhtaniemi I, Forrest S \& Aittomäki K 2002 A novel mutation in the FSH receptor inhibiting signal transduction and causing primary ovarian failure. Journal of Clinical Endocrinology and Metabolism 87 1151-1155. (https://doi.org/10.1210/ jcem.87.3.8319)

Enea C, Boisseau N, Fargeas-Gluck MA, Diaz V \& Dugue B 2011 Circulating androgens in women: exercise-induced changes. Sports Medicine $\mathbf{4 1}$ 1-15. (https://doi.org/10.2165/11536920-000000000-00000)

Esser KA, Harpole CE, Prins GS \& Diamond AM 2009 Physical activity reduces prostate carcinogenesis in a transgenic model. Prostate 69 1372-1377. (https://doi.org/10.1002/pros.20987)

Ferrante C, Orlando G, Recinella L, Leone S, Chiavaroli A, Di Nisio C, Shohreh R, Manippa F, Ricciuti A, Vacca M et al. 2016 Central inhibitory effects on feeding induced by the adipo-myokine irisin. European Journal of Pharmacology 791 389-394. (https://doi.org/10.1016/j. ejphar.2016.09.011)

Georgopoulos NA \& Roupas ND 2016 Impact of intense physical activity on puberty and reproductive potential of young athletes. In Exercise and Human Reproduction, pp. 239-251. Eds D Vaamonde, S du Plessis \& A Agarwal. New York, NY: Springer.

Gossell-Williams M, Davis A \& O'Connor N 2006 Inhibition of testosteroneinduced hyperplasia of the prostate of Sprague-Dawley rats by pumpkin seed oil. Journal of Medicinal Food 9 284-286. (https://doi.org/10.1089/ jmf.2006.9.284)

Guéritat J, Lefeuvre-Orfila L, Vincent S, Crétual A, Ravanat JL, GratasDelamarche A, Rannou-Bekono F \& Rébillard A 2014 Exercise training combined with antioxidant supplementation prevents the antiproliferative activity of their single treatment in prostate cancer through inhibition of redox adaptation. Free Radical Biology and Medicine 77 95-105. (https://doi.org/10.1016/j.freeradbiomed.2014.09.009)

Gurd B \& Klentrou P 2003 Physical and pubertal development in young male gymnasts. Journal of Applied Physiology 95 1011-1015. (https:// doi.org/10.1152/japplphysiol.00483.2003)

Jang HB, Kim HJ, Kang JH, Park SI, Park KH \& Lee HJ 2017 Association of circulating irisin levels with metabolic and metabolite profiles of Korean adolescents. Metabolism: Clinical and Experimental 73 100-108. (https://doi.org/10.1016/j.metabol.2017.05.007)

Jewo PI, Duru FI, Fadeyibi IO, Saalu LC \& Noronha CC 2012 The protective role of ascorbic acid in burn-induced testicular damage in rats. Burns $\mathbf{3 8}$ 113-119. (https://doi.org/10.1016/j.burns.2011.02.009) 
Jiang Q, Zhang Q, Lian A \& Xu Y 2017 Irisin stimulates gonadotropins gene expression in tilapia (Oreochromis niloticus) pituitary cells. Animal Reproduction Science 185 140-147. (https://doi.org/10.1016/j. anireprosci.2017.06.018)

Jones SL, Farrell S, Gregory JG \& Pfaus JG 2013 Sensitization of sexual behavior in ovariectomized rats by chronic estradiol treatment. Hormones and Behavior 64 8-18. (https://doi.org/10.1016/j.yhbeh.2013.04.012)

Kim HS, Shin JH, Moon HJ, Kim TS, Kang IH, Seok JH, Kim IY, Park KL \& Han SY 2002 Evaluation of the 20-day pubertal female assay in Sprague-Dawley rats treated with DES, tamoxifen, testosterone, and flutamide. Toxicological Sciences 67 52-62. (https://doi.org/10.1093/ toxsci/67.1.52)

Korenbrot CC, Huhtaniemi IT \& Weiner RI 1977 Preputial separation as an external sign of pubertal development in the male rat. Biology of Reproduction 17 298-303. (https://doi.org/10.1095/biolreprod17.2.298)

La Marca A, Grisendi V \& Griesinger G 2013 How much does AMH really vary in normal women? International Journal of Endocrinology 2013 959487. (https://doi.org/10.1155/2013/959487)

Leal-Cerro A, Gippini A, Amaya MJ, Lage M, Mato JA, Dieguez C \& Casanueva FF 2003 Mechanisms underlying the neuroendocrine response to physical exercise. Journal of Endocrinological Investigation 26 879-885. (https://doi.org/10.1007/BF03345239)

Lee P, Linderman JD, Smith S, Brychta RJ, Wang J, Idelson C, Perron RM, Werner CD, Phan GQ, Kammula US et al. 2014 Irisin and FGF21 are cold-induced endocrine activators of brown fat function in humans. Cell Metabolism 19 302-309. (https://doi.org/10.1016/j. cmet.2013.12.017)

Liu S, Du F, Li X, Wang M, Duan R, Zhang J, Wu Y \& Zhang Q 2017 Effects and underlying mechanisms of irisin on the proliferation and apoptosis of pancreatic $\beta$ cells. PLOS ONE 12 e0175498. (https://doi.org/10.1371/ journal.pone.0175498)

Louis GMB, Gray LE, Marcus M, Ojeda SR, Pescovitz OH, Witchel SF, Sippell W, Abbott DH, Soto A, Tyl RW et al. 2008 Environmental factors and puberty timing: expert panel research needs. Pediatrics 121 (Supplement 3) S192-S207. (https://doi.org/10.1542/peds.1813E)

Macklon NS \& Fauser BC 2001 Follicle-stimulating hormone and advanced follicle development in the human. Archives of Medical Research 32 595-600. (https://doi.org/10.1016/s0188-4409(01)00327-7)

Manna I, Jana K \& Samanta PK 2004 Intensive swimming exercise-induced oxidative stress and reproductive dysfunction in male Wistar rats: protective role of $\alpha$-tocopherol succinate. Canadian Journal of Applied Physiologye 29 172-185. (https://doi.org/10.1139/h04-013)

Marcondes FK, Bianchi FJ \& Tanno AP 2002 Determination of the estrous cycle phases of rats: some helpful considerations. Brazilian Journal of Biology 62 609-614. (https://doi.org/10.1590/s151969842002000400008)

Martos-Moreno GA, Chowen JA \& Argente J 2010 Metabolic signals in human puberty: effects of over and undernutrition. Molecular and Cellular Endocrinology 324 70-81. (https://doi.org/10.1016/j.mce.2009.12.017)

Ojeda SR \& Urbanski HF 1994 Puberty in the rat. In The Physiology of Reproduction, pp. 363-410. Eds E Knobil \& JD Neill. New York, NY: Raven Press.

Ozcan S, Ulker N, Bulmus O, Yardimci A, Ozcan M \& Canpolat S 2020 The modulatory effects of irisin on Asprosin, leptin, glucose levels and lipid profile in healthy and obese male and female rats. Archives of Physiology and Biochemistry in press. (https://doi.org/10.1080/138134 55.2020.1722706)

Parandin R, Yousofvand N \& Ghorbani R 2012 The enhancing effects of alcoholic extract of Nigella sativa seed on fertility potential, plasma gonadotropins and testosterone in male rats. Iranian Journal of Reproductive Medicine 10 355-362.

Patton GC \& Viner R 2007 Pubertal transitions in health. Lancet 369 1130-1139. (https://doi.org/10.1016/S0140-6736(07)60366-3)

Poretsky L, Islam J, Avtanski D, Lin YK, Shen YL, Hirth Y, Lesser M, Rosenwaks Z \& Seto-Young D 2017 Reproductive effects of irisin: initial in vitro studies. Reproductive Biology 17 285-288. (https://doi. org/10.1016/j.repbio.2017.05.011)

Reinehr T, Elfers C, Lass N \& Roth CL 2015 Irisin and its relation to insulin resistance and puberty in obese children: a longitudinal analysis. Journal of Clinical Endocrinology and Metabolism 100 2123-2130. (https://doi. org/10.1210/jc.2015-1208)

Roa J \& Tena-Sempere M 2014 Connecting metabolism and reproduction: roles of central energy sensors and key molecular mediators. Molecular and Cellular Endocrinology 397 4-14. (https://doi.org/10.1016/j. mce.2014.09.027)

Shiorta M, Kawashima J, Nakamura T, Ogawa Y, Kamiie J, Yasuno K, Shirota K \& Yoshida M 2012 Delayed effects of single neonatal subcutaneous exposure of low-dose $17 \alpha$-ethynylestradiol on reproductive function in female rats. Journal of Toxicological Sciences 37 681-690. (https://doi.org/10.2131/jts.37.681)

Shokri S, Aitken RJ, Abdolvahhabi M, Abolhasani F, Ghasemi FM, Kashani I, Ejtemaeimehr S, Ahmadian S, Minaei B, Naraghi MA et al. 2010 Exercise and supraphysiological dose of nandrolone deconoate increase apoptosis in spermatogenic cells. Basic and Clinical Pharmacology and Toxicology 106 324-330. (https://doi.org/10.1111/j.1742-7843.2009.00495.x)

Tanaka Y, Nakada K, Moriyoshi M \& Sawamukai Y 2001 Appearance and number of follicles and change in the concentration of serum FSH in female bovine fetuses. Reproduction 121 777-782. (https://doi. org/10.1530/rep.0.1210777)

Tekin S, Beytur A, Erden Y, Beytur A, Cigremis Y, Vardi N, Turkoz Y, Tekedereli I \& Sandal S 2019 Effects of intracerebroventricular administration of irisin on the hypothalamus-pituitary-gonadal axis in male rats. Journal of Cellular Physiology 234 8815-8824. (https://doi. org/10.1002/jcp.27541)

Tymchuk CN, Barnard RJ, Heber D \& Aronson WJ 2001 Evidence of an inhibitory effect of diet and exercise on prostate cancer cell growth. Journal of Urology 166 1185-1189. (https://doi.org/10.1016/S00225347(05)65943-5)

Visser JA, Schipper I, Laven JS \& Themmen AP 2012 Anti-Müllerian hormone: an ovarian reserve marker in primary ovarian insufficiency. Nature Reviews: Endocrinology 8 331-341. (https://doi.org/10.1038/ nrendo.2011.224)

Wahab F, Shahab M \& Behr R 2016 Hypothesis: irisin is a metabolic trigger for the activation of the neurohormonal axis governing puberty onset. Medical Hypotheses 95 1-4. (https://doi.org/10.1016/j. mehy.2016.08.003)

Witkoś J \& Wróbel P 2019 Menstrual disorders in amateur dancers. BMC Women's Health 19 87. (https://doi.org/10.1186/s12905-019-0779-1)

Yakubu MT, Akanji MA, Oladiji AT \& Adesokan AA 2008 Androgenic potentials of aqueous extract of Massularia acuminata (G. Don) Bullock ex Hoyl. stem in male Wistar rats. Journal of Ethnopharmacology 118 508-513. (https://doi.org/10.1016/j.jep.2008.05.020)

Yüce A, Türk G, Çeribaşi S, Sönmez M, Çiftçi M \& Güvenç M 2013 Effects of cinnamon (C innamomum zeylanicum) bark oil on testicular antioxidant values, apoptotic germ cell and sperm quality. Andrologia 45 248-255. (https://doi.org/10.1111/and.12000)

Zhang Q, Lin Y, Zhang XY \& Wang DH 2015 Cold exposure inhibits hypothalamic Kiss-1 gene expression, serum leptin concentration, and delays reproductive development in male Brandt's vole (Lasiopodomys brandtii). International Journal of Biometeorology 59 679-691. (https:// doi.org/10.1007/s00484-014-0879-4)

Received 6 February 2020

First decision 2 March 2020

Revised manuscript received 11 May 2020

Accepted 26 May 2020 